\title{
AUTOMATIC POWER FACTOR CORRECTION USING CAPACITOR BANKS
}

\author{
Mrs. D.Vinodini \\ Assistant Professor, \\ EEE Department, Vel \\ Tech, Chennai, India,
}

\author{
V. Mohana priya, \\ B.E. Student, \\ Vel Tech, \\ Chennai, India
}

\author{
M. Nivetha \\ B.E. Student, \\ Vel Tech, \\ Chennai, India
}

\author{
D. Sindhuja \\ B.E. Student, \\ Vel Tech, \\ Chennai, India
}

\begin{abstract}
The correction of power factor of electric load could be a problematic issue which is common to entire industrial companies. Previously, the correction of power factor was performed to adjust bank of electrical phenomenon properly. Automatic power factor corrector (APFC) utilize load capacitance bank is useful to implement facility issue correction. Planned machinecontrolled project consists of activity that is worth the correction of power factor of load victimization microcontroller. Design of this self-adjusting power issue correction is to confirm the complete facility perpetually protective unit power issue. A package as well as hardware needed to perform instructed automatic measure devoted as well as its operation described. APFC, therefore help us to reduce the time needed to correct as a power factor that support to extend organization
\end{abstract}

Keywords - APFC, Apparent power, Capacitor bank, Power factor, power factor, solid state relay, precision rectifier, super diode, phase measurement, AC signal measurement, Arduino

\section{INTRODUCTION}

Majority of the masses within the industries area unit extremely inductive at nature like induction motors, AC/DC drives, attachment machines, arc furnace, fluorescent Lights, electric controls as well as computers. It could also be a number of series of resistive masses to heaters as well as bulbs incandescent (Zheng and Zhang, 2017). Terribly seldom industries could consist of electrical phenomenon masses like synchronous motors . Net industrial load is extremely inductive inflicting awfully poor power insulant issue. If the issue of poor power is not corrected, business would force a great require of Electricity Board as well as conjointly can hurt a punishment of issue as poor power. Customary apply is to attach power capacitance within facility of acceptable places with recompense inductive nature of load (Ali et al., 2018).

\section{PROBLEM STATEMENTS}

An electric charge that works with $\mathrm{AC}$ needs evident power that has active and reactive power. Real power denotes power truly absorbed to load. The load repeatedly require to load as well as came back with ability supply, it's cyclic result, which occur once AC passes to load which contains a reactive part (Pawale et al.; Kabir et al., 2017).

The presence of reactive power means that important power is evident power and the electrical load incorporates the power issue of one (Singh et al., 2010; Rueda-Medina et al., 2012). Reactive power will increase the present flowing among ability supply and also the load that will increase the ability of transmission loss as well as the distribution lines. It ends up at operation as well as money loss of electric companies (Lu et al., 2017; Khan and Owais, 20169; Bastos et al., 2016).

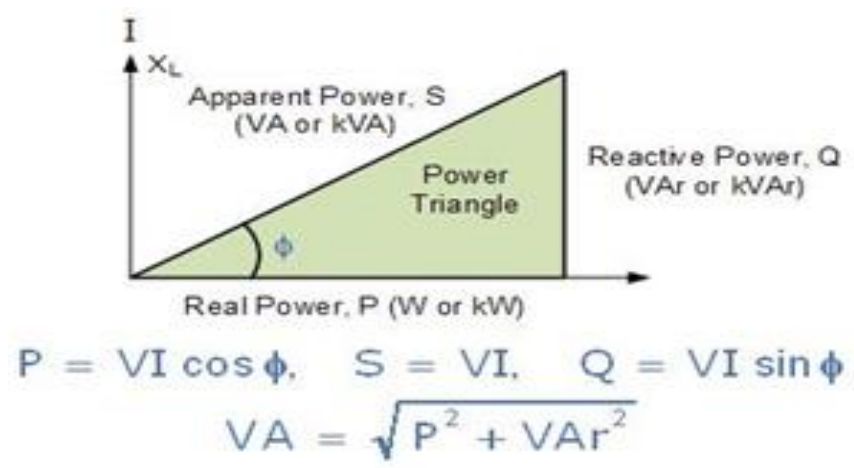

Figure 1 Power components

The power factor is that invisible issue that means good loss of voltage as well as jointly harms an electric instrumentality (Lopes et al., 2007; Singh et al., 2012; Vargas et al., 2008). The problem of power is that relationship of magnitude of real power with all power (evident power).

$\mathrm{S}=$ Total power of Generator (or used)

$\mathrm{P}=$ Power consumed at load (real power)

$\mathrm{Q}=$ Reactive power stored at magnetic field.

Therefore, power corporations require customers, especially to giant masses, take care of power factors higher than specific quantity (usually zero.90 or greater) subject with extra charges. Electric engineers consists of generation, transmission, distribution as well as consumption of wattage interest within power issue of masses as a result of power factors have an effect on efficiencies and prices for each the wattage business and therefore the shoppers.

Moreover, an inflated operative price, reactive power will need optimization of wiring, switch, circuit breaker, 
transformers as well as transmission lines to maximum current capacities.

Correction of the power problem to regulate facility issue of an $\mathrm{AC}$ load or $\mathrm{AC}$ power gear mechanism with unit (1.00) to numerous methods, easy methods encompass the change at out of capacitance banks or inductors that react cancel as effects of inductive or electrical phenomenon of load, jointly and severally.

Non-linear masses produce harmonic currents additionally with first AC current. Easy correction method delineate higher than don't eliminate reactive power at harmonic frequencies, therefore additional refined methods for non-linear loads should not be corrected.

\section{BLOCK DIAGRAM}

The following figure of automatic power issue correction system. Input circuit is implemented to identify power supply. AC input i.e., $230 \mathrm{~V}$ of mains is reduced to electrical device $12 \mathrm{~V}$ as well as powered with rectifier. Output acquired as rectifier could be rhythmic voltage DC. Therefore, to urge a pure voltage DC, rectifier voltage output is powered with filter to get rid AC of any elements gift once rectified.

The voltage and current signals supplied, taken to potential transformer as well as current transformer. Two sinusoidal waveforms become switched with square waves via two zero crossing detections. Microcontroller uses these digital square waves to compute phase difference as well as power factor.

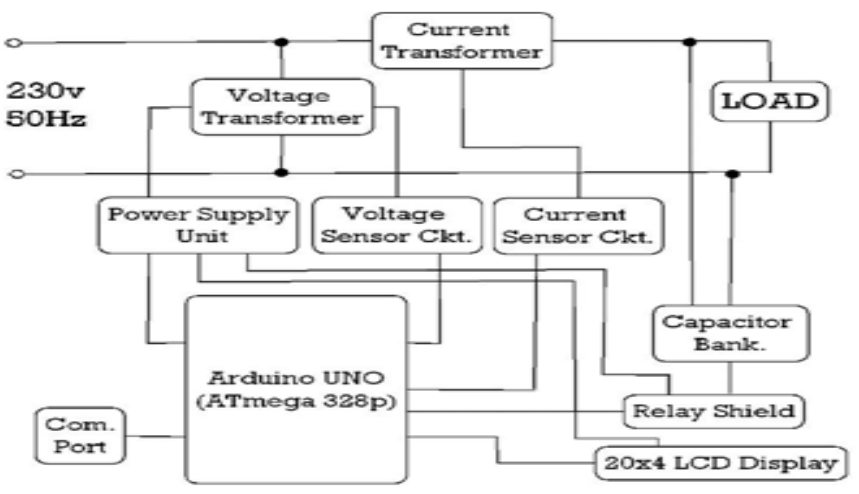

Figure 2 Block Diagram of APFC Unit

An electrical phenomenon load bank is employed that evolves the electrical load, implemented with AN power supply as well as changes or dissipates power output resulting sources due to the method facilitate to boost power issue.

As status of APFC system had shown on LCD as a problem of calculated, insulating or main power etc. Microcontroller used is Arduino UNO (ATmega 328p) that denotes heart as well as brain of whole system APFC. Takes information of user as well as nil crossing current, voltage wave forms. To control PRN electric condenser bank to repair the main or insulant power issue.
IV. HARSWARE IMAGE

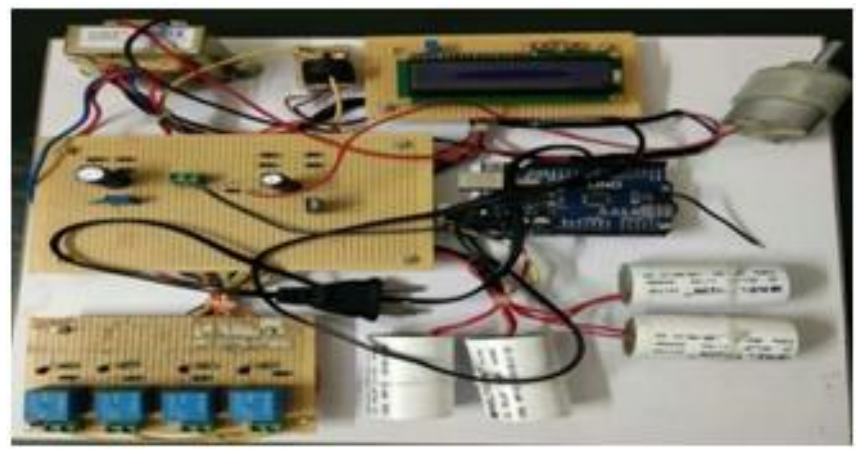

Figure 3 Hardware image of APFC unit

\section{HARDWARE DESCRPTION}

This project kit has transformer, current transformer, LED, voltage controller, Arduino, electromagnetic relay, capacitor banks, rectifier, motor. The supply for the assembly kit is directly taken from the $230 \mathrm{~V}$ ac supply. Initially the $230 \mathrm{~V}$ supply is given to the step down transformer; it gives the voltage to rectifier at the rate of $12 \mathrm{~V}$. Now the rectifier again reduces its value to $5 \mathrm{~V}$, given to the motor. Since the value of the motor input is too small to display, power factor for the system is shown with the use of LED Display. Arduino is the open source controller. It is the intelligent chip of microcontroller having memory, software, and hardware. It can generate the pulse. It is an interactive object commonly using in the electronics. Capacitor banks are used to power factor increment. If capacitors banks are parallel, power factor will be increased. Electromagnetic relays are used for tripping the capacitor banks to switch ON/OFF cross detection that provides square waves at digital format. The microcontroller uses these digital waveforms to compute power factor. Microcontroller makes the decision to change the suitable capacitance bank to recompense as power factor.

The following figure represents the situation when the power factor is very poor in 0.767 . Low power factor is not accepted according to the standard due to low or low power factors affect efficiency as well as costs for both electric power industry as well as consumers. Moreover, to maximize the operating costs, reactive power may need the use of wiring, switches, circuit breakers, transformers as well as transmission lines to large current capacity. The poor power factor must be compensated to capacitor bank.

\section{SimUlation AND ObSERVATION}

Simulation tool utilized to evaluate APFC system is Proteus VSM. It is an interactive circuit simulation tool of associated degree within style environment. It is possible to draw a complete circuit of microcontroller mainly on a system, therefore, take an interactive look, entire from identical package. To tutorial user as well as engineering methods, ISIS is utilized together to make attractive schemes. 


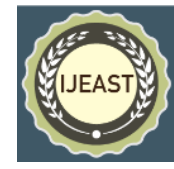

The following figure displays, however, APFC system appears as once it runs interactively.

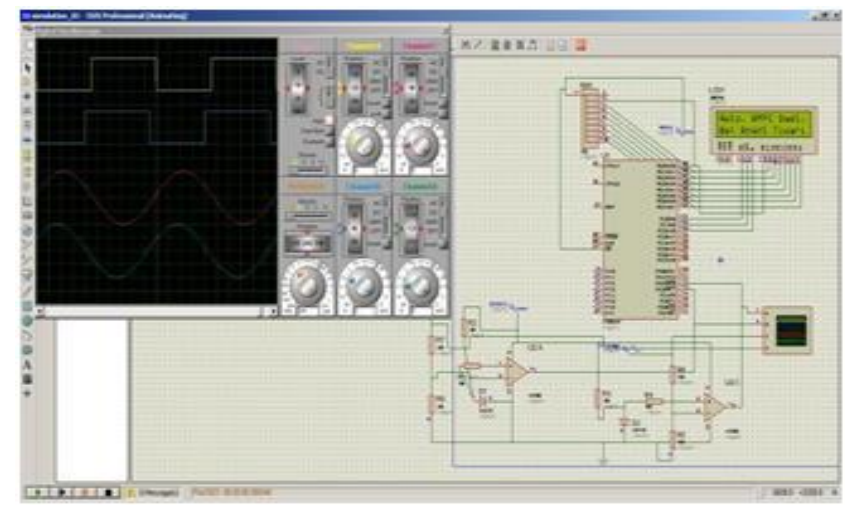

Figure 4 APFC Simulation on Proteus VSM

This displays input as well as voltage waveform to phase variance. Waveform is powered with zero crossing detection that implements square waves at digital format. Microcontroller uses these digital waveforms to compute power factor. Microcontroller makes the decision to change the suitable blank capacitance with recompense to power factor.

The following figure denotes the situation of power factor is very poor in 0.767 . Low power factor is not received due to standard as low or less power factors affect efficiency as well as costs of electric power industry as well as consumers. Moreover, to maximize operating costs, reactive power may need the use of wiring, switches, circuit breakers, transformers as well as transmission lines to maximum current capacity. The poor power factor must be compensated to capacitor bank.

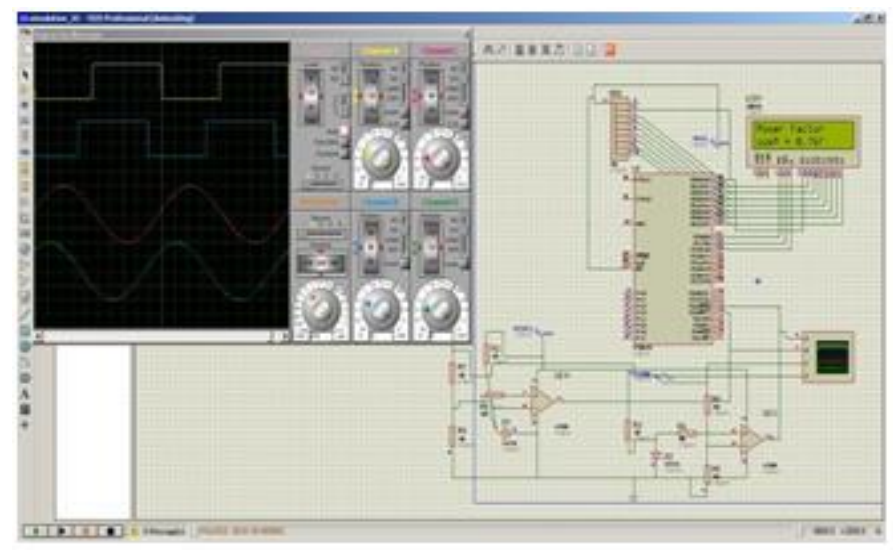

Figure 5 Poor power factor detection

Superior to detect a poor power factor, APFC system changes one capacitance in time with group of eight capacitors. If the objective needed to reach the power factor is satisfied the next cycle is repeated; otherwise, the switch of capacitor will continue until the compensation is not under control. The following figure displays APFC system as system reaches the optimal value of power factor 0.940 is needed.

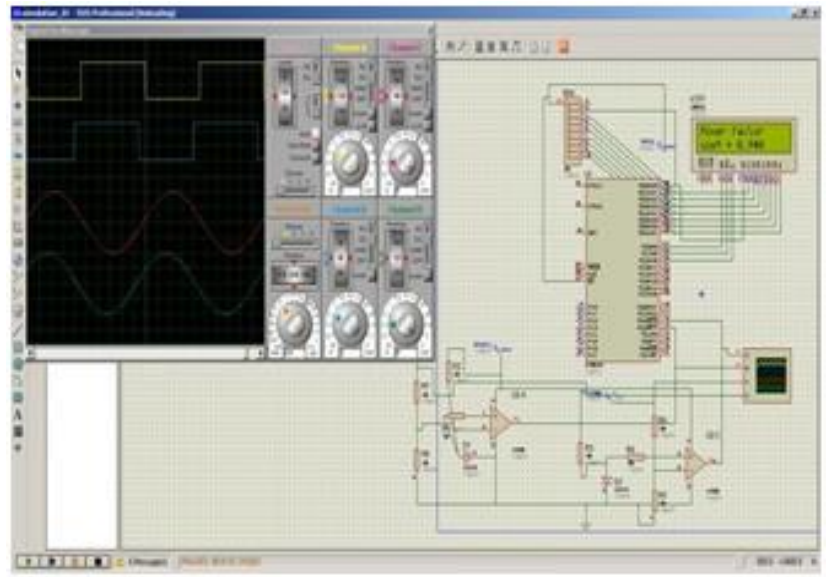

Figure 6 Improved power factor by APFC

Therefore, we perceive as prior implementation of APFC system at active physical world, to evaluate the proof of concept utilize Proteus VSM.

\section{RESUlts AND CONCLUSIONS}

Looking at all aspects of power factor, it is clear that power factor denotes most important part of both utility and consumer. Utility companies receive rid of power losses, though consumers are free of penalty charges to low power factor.

By installing power capacitance of adequate size at circuit, power factor is performed as well as value is close with 0.9 to 0.95, thus reduce the line loss as well as perform the organization of plant. When utilizing this system APFC, organization system increases considerably.

\section{FUTURE ENHANCENTS}

Automotive power issue mistreatment electrical phenomenon load banks are incredibly economical because it eliminates value to reduce power consumed as provision. Because it works mechanically, manpower isn't this machine-controlled Power issue method of mistreatment electrical phenomenon load banks is utilized to industrial purpose within future.

\section{REFERENSES}

1. Ali, W., Farooq, H., Jamil, M., Rehman, A., Taimoor, R., and Ahmad, M. (2018). Automatic Power Factor Correction for Single Phase Domestic Loads by Means of Arduino Based TRIAC Control of Capacitor Banks. 2018 2Nd International Conference On Energy Conservation And Efficiency (ICECE), (pp. 72-76).

2. Bastos, A., Santoso, S., and Biyikli, L. (2016). Analysis of power factor over correction in a 
distribution feeder. 2016 IEEE/PES Transmission And Distribution Conference And Exposition (TandD). (pp.1-5)

3. Kabir, Y., Mohsin, Y., and Khan, M. (2017). Automated power factor correction and energy monitoring system. 2017 Second International Conference on Electrical, Computer and Communication Technologies (ICECCT), (pp. 1-5).

4. Khan, M., and Owais, M. (2016). Automatic power factor correction unit. 2016 International Conference On Computing, Electronic And Electrical Engineering (ICE Cube), Pp. 283-288,, (pp. 283-288),.

5. Lopes, J., Hatziargyriou, N., Mutale, J., Djapic, P., and Jenkins, N. (2007). Integrating distributed generation into electric power systems: A review of drivers, challenges and opportunities. Electric Power Systems Research, 77(9), 1189-1203.

6. Lu, Y., Qiu, D., Zhang, B., Chen, Y., and Jiang, Y. (2017). Implementation of power factor corrector with fractional capacitor. 2017 IEEE International Symposium On Circuits And Systems (ISCAS), (pp. 14).

7. Pawale, T., Motekar, R., Chakrasali, R., and Halbhavi, S. (2017). An experimental design approach for power factor correction using PLC. 2017 International Conference On Smart Technologies For Smart Nation (Smarttechcon).

8. Rueda-Medina, A., and Padilha-Feltrin, A. (2013). Distributed Generators as Providers of Reactive Power Support-A Market Approach. IEEE Transactions On Power Systems, 28(1), 490-502.

9. Singh, M., Khadkikar, V., and Chandra, A. (2011). Grid synchronisation with harmonics and reactive power compensation capability of a permanent magnet synchronous generator-based variable speed wind energy conversion system. IET Power Electronics, 4(1), 122-130.

10. Singh, R., and Goswami, S. (2010). Optimum allocation of distributed generations based on nodal pricing for profit, loss reduction, and voltage improvement including voltage rise issue. International Journal Of Electrical Power and Energy Systems, 32(6), 637-644.

11. Vargas, R., Rodriguez, J., Ammann, U., and Wheeler, P. (2008). Predictive Current Control of an Induction Machine Fed by a Matrix Converter With Reactive Power Control. IEEE Transactions On Industrial Electronics, 55(12), 4362-4371.

12. Zheng, F., and Zhang, W. (2017). Long term effect of power factor correction on the industrial load: A case study. 2017 Australasian Universities Power Engineering Conference (AUPEC). (pp. 1-50), 